Please ensure that your abstract fits into one column on one page and complies with the Instructions to Authors available from the Abstract Submission web page.

\title{
Metal/Silicate Partitioning Experiments in a Diamond-Anvil Cell; Issues and Applications for Fe- Si-O-Mg Core Chemical Evolution Models
}

\author{
KEI HIROSE ${ }^{1,2 *}$ AND GEORGE HELFFRICH ${ }^{1}$
}

${ }^{1}$ Earth-Life Science Institute, Tokyo Institute of Technology, Tokyo, Japan

(*correspondence: kei@elsi.jp)

${ }^{2}$ Department of Earth and Planetary Science, The University of Tokyo, Tokyo, Japan

Recent core formation models show that metals were in chemical equilibrium with silicate melt at high pressure and temperature $(P-T)$, typically about $50 \mathrm{GPa}$ and $3500 \mathrm{~K}$. Experiments using a laser-heated diamond-anvil cell (DAC) have examined metal/silicate partitioning of $\mathrm{Si}, \mathrm{O}, \mathrm{Mg}$ and trace elements at such high $P-T$, which suggests original core composition and subsequent chemical evolution to the present one. Earlier DAC studies usually examine metal/silicate partitioning of a cation $M$ with valence $+n$ by considering the exchange reaction $(\mathrm{n} / 2) \mathrm{Fe}+\mathrm{MO}_{\mathrm{n} / 2}=$ $(\mathrm{n} / 2) \mathrm{FeO}+\mathrm{M}$. However, the feasibility of the exchange relies on the certainty that the experimental $P-T$ can shift the iron-wüstite equilibrium sufficiently to induce detectable $\mathrm{MO}_{\mathrm{n} / 2}$ dissociation. In the $\mathrm{Mg}-\mathrm{Si}-\mathrm{O}$ system previously examined in a DAC, fit incoherence of plots of $\log \left(D_{\mathrm{Mg}}\right)$ vs $\log \left(f \mathrm{O}_{2}\right)$ relative to the $\mathrm{Fe}-\mathrm{FeO}$ buffer show that the shift is difficult to achieve with the individual $\mathrm{Mg}-\mathrm{MgO}$ and $\mathrm{Si}-\mathrm{SiO}_{2}$ equilibria and iron. This indicates that reduction of $\mathrm{M}^{\mathrm{n}+}$ to $\mathrm{M}^{0}$ by $\mathrm{Fe}$ is not possible due to limitations on exchange of $\mathrm{O}$ between the metal, silicate, and experimental environment in the DAC. Hence an alternative approach to handling the exchange reaction is required. We found that the metal/silicate $\mathrm{Mg}$ partitioning occurs through the different reaction $\mathrm{Si}+2 \mathrm{MgO}=\mathrm{SiO}_{2}+2 \mathrm{Mg}$, not only in our experiments but also all previous DAC experiments reported in the literature. Accordingly metal/silicate partitioning of $\mathrm{O}$ is governed by the reaction $\mathrm{Si}+\mathrm{O}=\mathrm{SiO}_{2}$, and existing DAC data reveal some pressure effect on the partitioning of $\mathrm{O}$ into metal. These suggest that 1 ) $\mathrm{Si}+\mathrm{O}$ solubility in molten Fe diminishes at core pressures, which drives $\mathrm{SiO}_{2}$ crystallization in the core, and 2) $>1.8 \mathrm{wt} \% \mathrm{Mg}$ in the core leads to $\mathrm{MgO}$ exsolution. The joint $\mathrm{SiO}_{2}+\mathrm{MgO}$ exsolution means the exsolution of solid $\mathrm{SiO}_{2}$ and $(\mathrm{Mg}, \mathrm{Fe})$-silicate melts that transfer core-hosted elements to the mantle. 